\section{Medical Principles} and Practice

\section{Mazen Al-Essa ${ }^{\text {a }}$ \\ Ahmed Kazi a \\ Adel Al-Hunayan ${ }^{\mathrm{b}}$ \\ L.V. Deverajan ${ }^{\mathrm{a}}$}

a Maternity Hospital and

b Ibn Sina Hospital, Kuwait

\section{Key Words}

Nonimmune hydrops

Urogenital sinus

\title{
Non-Immune Hydrops Associated with Urogenital Sinus
}

\begin{abstract}
Objective and Importance: To report an unknown association between nonimmune hydrops and a case of urogenital sinus. Clinical Presentation: A newborn girl presented with gross fetal and neonatal hydrops and was managed successfully. She was then extensively investigated for the cause of hydrops, and was only found to have a urogenital anomaly that was managed by temporary external drainage. Conclusion: Urogenital sinus anomalies may be added to the list of causes and associations of nonimmune hydrops fetalis.
\end{abstract}

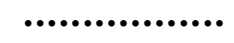

\section{Introduction}

Nonimmune hydrops fetalis is associated with many types of diseases and conditions [1]. Urethral obstruction and congenital anomalies of the uterus and vagina are among the genitourinary conditions of associations.

Urogenital sinus is defined as a common channel into which both the urinary and genital tracts open. It is one of the rare congenital malformations that has a wide spectrum of urogenital anomalies with variable modes of presentation caused by a lack of development of the urogenital sinus and its derivatives [2, $3,5]$.

\begin{tabular}{ll}
\hline KARGER & @ 1998 S. Karger AG, Basel \\
Fax +41 61306 1234 $34-7571 / 98 / 0073-0226 \$ 15.00 / 0$ \\
$\begin{array}{l}\text { E-Mail karger@karger.ch } \\
\text { www.karger.com }\end{array}$ & $\begin{array}{l}\text { Accessible online at: } \\
\text { http://BioMedNet.com/karger }\end{array}$
\end{tabular}

We report a case of fetal and neonatal hydrops that was associated with urogenital sinus in a newborn girl.

\section{Case Report}

A 22-year-old woman was referred to the Maternity Hospital at 32 weeks of gestation with polyhydramnios. An ultrasound scan on the referral day showed fetal hydrops with the suspicion of hydronephrosis and hydroureter. She had normal pregnancies previously ending in 2 normal children. Because of the gross ascites and hydrops the mother underwent lower segment cesarean section to give birth to a baby girl weighing 3,660 $\mathrm{g}$ with gross hydrops. The baby's Apgar score was 2 and 6 at 1 and 5 min, respectively.

Dr. Mazen Al-Essa

Department of Pediatrics, Faculty of Medicine, Kuwait University PO Box 24923, 13110 Safat (Kuwait)

Tel. +965 531-9486, Fax +965 533-8940

E-Mail mazen@hsc.kuniv.edu.kw 


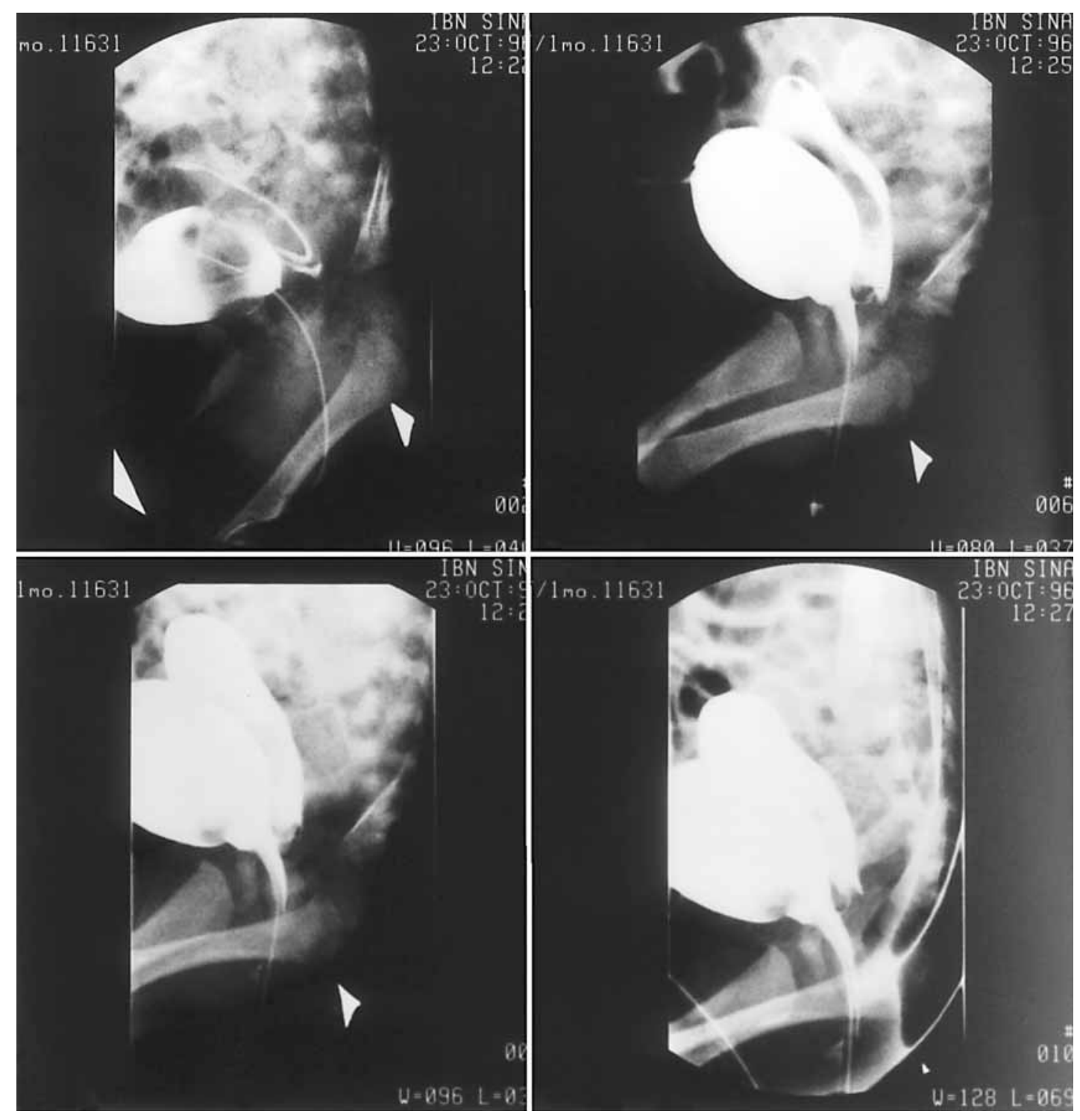

Fig. 1. Voiding cystourethrogram of the patient showing the filling of the vagina with dye.

The baby was resuscitated and then transferred to the neonatal intensive care unit (NICU) for further treatment. In the NICU, the baby was managed successfully with aggressive ventilation, surfactant therapy and careful fluid management with colloids in the form of 12-hourly albumin infusion, followed by low-

Non-Immune Hydrops Associated with Urogenital Sinus dose furosemide. She remained stable with regard to the vital signs and basic hematological and biochemical investigations including the renal function test. She lost $1,400 \mathrm{~g}$ over 7 days and could be extubated on the 10 th day of life. The baby had a lower abdominal mass that was palpable only when the ascites was cleared,

Med Principles Pract 1998;7:226-229 227 
Fig. 2. a The urogenital sinus found in our case. $\mathbf{b}$ when it got obstructed. $\mathrm{B}=$ Bladder; $\mathrm{R}=$ rectum; $\mathrm{S}=$ symphysis pubis; $\mathrm{U}=$ uterus; $\mathrm{URS}=$ urogenital sinus; $\mathrm{V}=$ vagina.

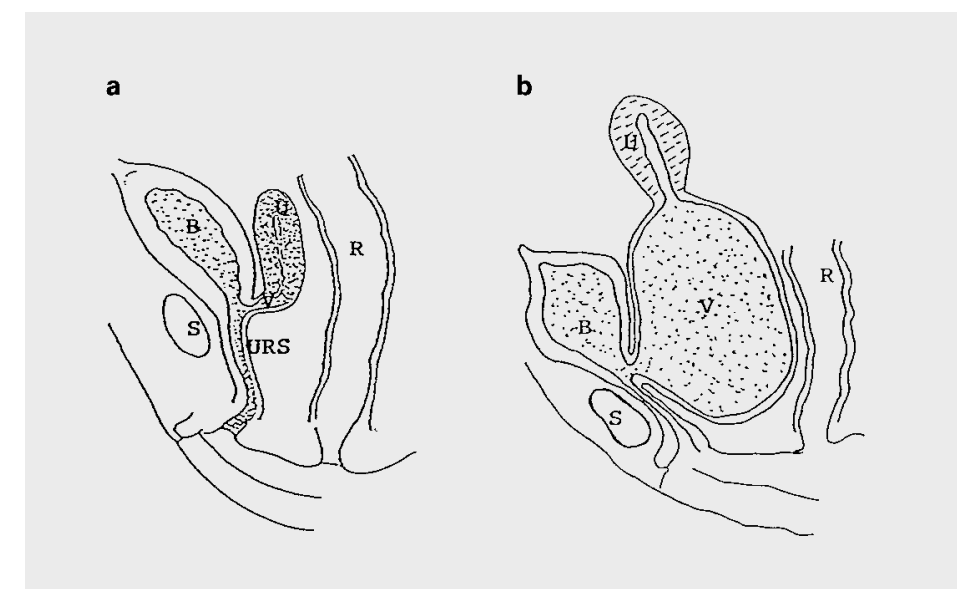

and at that point the absence of the vaginal opening was detected.

The baby had the following investigations: (1) Abdominal ultrasound which revealed a resolving hydronephrosis and hydroureter and an abdominal mass that could be not clearly defined. (2) Findings in the CAT scan of the abdomen were not helpful. (3) Micturating cystourethrogram of the patient showed that the dye filled the bladder initally. Upon voiding, however, the mass could be identified as having a fistulous connection with the bladder but it was not definable. There was no vesicoureteric reflux but it showed the filling of the vagina with the dye upon micturition (fig. 1). (4) Cytoscopy was done under general anesthesia which showed a vaginal opening into the proximal urethra just below the bladder neck area. The opening was cannulated and urine was drained from the vagina confirming the diagnosis of urogenital sinus. A percutaneous temporary tube vaginostomy was then inserted.

The baby continued to do well in spite of one episode of Pseudomonas sepsis. She responded well to systemic antibiotics, and during her stay in the NICU she was additionally investigated for other known causes of hydrops fetalis. These included blood film examination, urine analysis, liver function tests, hemoglobin electrophoresis, immunoglobulin levels, viral studies, $\alpha$-fetoprotein, and $\alpha_{1}$-antitrypsin levels, all of which proved to be normal. An echocardiogram showed a normal heart, and a chromosomal analysis showed a karyotype of $46 \mathrm{XX}$. The baby had cholestasis which disappeared along with the hydronephrosis- and the hydroureter once the mass was decompressed. This was confirmed by ultrasound examination.

On follow-up, the baby had been doing well but the external vaginostomy needed dilatation. She had urinary tract infection that was treated, and the baby was commenced on prophylactic antibiotics. The renal function remained normal.

\section{Discussion}

In the embryonic development, the primitive hindgut, or cloaca, is divided by the urorectal septum into an anterior urogenital sinus and the dorsal hindgut, which becomes the rectum and the anal canal [4]. The urogenital sinus gives rise to the bladder and urethra, and the distal vagina.

In the female there are three types of urogenital sinus abnormalities resulting from defective development in this location: (1) vaginal obstruction or atresia, (2) persistent urogenital sinus abnormality and (3) persistent cloacal anomalies. Our case fits with the second variety [3] (fig. 2).

On the other hand, nonimmune hydrops remains one of the challenging conditions in diagnosis and treatment in perinatal medicine 
$[1,2]$. Several causes and associations have been reported, and in most of the associations the mechanism of the hydrops formation is not fully understood [1]. Among the genitourinary conditions are the congenital nephrotic syndrome, urethral obstruction and renal dysplasia, polycystic kidneys, renal vein obstruction and congenital abnormalities of the vagina and uterus. In $50 \%$ of the cases the causes remain unknown, and poor prognosis is seen in up to $80 \%$ of the conditions.

\section{References}

1 Stephenson T, Zuccollo J, Mohajer M: Diagnosis and management of non-immune hydrops in the newborn. Arch Dis Child 1994;70: F151-F154.

2 Holzgreve W, Holzgreve B, Curry CJ: Non-immune hydrops fetalis: Diagnosis and management. Semin Perinatol 1985;9:52-67.
3 Hensler TW: Genital anomalies: in Gillenwater JY, Grayhack JT, Howards SS, Duckett JU (eds): Adult and Pediatric Urology, ed. 3, St. Louis, Mosby, 1996, vol 3, pp 25412542.

4 Moore KI: The Developing Human Oriented Embryology, ed 4. London, Saunders, 1988.

5 Alexanders F, Kay R: Cloacal anomalies: Role of vesicotomy. J Pediatr Surg 1994;1:74-76. 